\title{
ФУНКЦИОНИРОВАНИЕ ЭТНОРЫНКОВ В ЭКОНОМИКЕ РЕГИОНОВ ЮГА РОССИИ
}

\author{
(c) 2018 Кетова Наталья Петровна \\ заслуженный деятель науки РФ \\ доктор экономических наук, профессор, зав. кафедрой «Маркетинг и коммуникации в бизнесе» \\ Южный федеральный университет \\ 344002, г. Ростов-на-Дону, ул. М. Горького, 88 \\ E-mail:kmik2012@mail.ru \\ (c) 2018 Овчинников Виктор Николаевич \\ Заслуженный деятель науки РФ, \\ доктор экономических наук, профессор \\ профессор-консультант кафедры управления развитием пространственно-экономических систем \\ Южный федеральный университет \\ 344002, г. Ростов-на-Дону, ул. М. Горького, 88 \\ E-mail: ovn@aaanet.ru
}

В статье представлены результаты разработки проблем: выявления функциональной роли этнических рынков в экономике регионов Юга России; идентификации их позиций и определения векторов ориентации на удовлетворение специфических видов спроса целевых аудиторий потребителей.

Ключевые слова: экономика региона, этнические рынки, целевые аудитории, этнические предпочтения покупателей, векторы ориентации, территориальное пространство.

Этнические рынки: специфика, условия формирования, субъектная определенность.

Этнорынки - достаточно сложный феномен, охватывающий совокупность экономических, демографических, расселенческих и межэтнических взаимоотношений, реализуемых в трансакциях. Функционирование таких рынков становятся одним из факторов развития социально-экономической среды в России и в других странах, но до сих пор остаётся мало изученным.

Локальный этнорынок (от англ. local market) - это рыночный сегмент национальной экономики, выделяемый по географическому, национально-этническому, товарному, функциональному и другим признакам [1]. Данный рынок предполагает концентрацию на одном или нескольких сегментах, отличающихся этноэкономической спецификой. Очевидно, что в этом смысле правомерно говорить лишь о рынках «B2C», т.е. рынках, на которых осуществляется купля-продажа товаров для конечного потребления товаров и услуг. Ибо на рынках «В2В», где осуществляется сбыт продукции производственно-технического назначения, предназначенной для производства других товаров и оказания услуг, предметы трансакций этноэкономической спецификой, практически, не обладают.

Под словом «локальный этнический рынок» предлагается понимать территориально ограниченную и этнически идентифицируемую часть регионального рынка, т.е. географическое пространство, на котором действуют рыночные субъекты коренного населения (представляющие сторону предложения, а, зачастую, и спроса), и имеют место соответствующие сегменты. При этом учитываются экономические, демографические, политические, социальные и другие условия функционирования данного пространства. Территориальное пространство этнорынка обычно не превышает размер основной административно-территориальной единицы рассматриваемой страны (область, округ, регион, штат). Но может ограничиться территорией города, поселка, городского района и т.п.

Проблемы функционирования этнических рынков рассматриваются в современной российской литературе, и ряд исследователей уделяют внимание именно таким рынкам. Так, Дятлов В.И. и Григоричев К.В., исследующие проблематику китайских и корейских этнорынков на Дальнем Востоке, пишут, что их можно считать стержневым элементом этнокластеров. 
Этнические рынки, по мнению этих авторов, стали играть важную экономическую, социальную и даже символическую роль в городском пространстве. Они быстро переросли простой формат торговых площадок и превратились в сложные и саморазвивающиеся социальные организмы, сгустки социальных связей, сетей, конфликтов, механизмов власти и контроля [2, c.35-37].

Характерные черты локального этнического потребительского рынка можно дифференцировать как общие и специфические. К числу общих правомерно отнести: спрос и предложение на рынке, объемы продаж, уровень жизни населения, его доходы, уровень и соотношение цен, размеры экспорта и импорта потребительских товаров, развитие инфраструктуры рынка и др. Специфические черты отражают различные грани особенностей локальных рынков: этно-исторические, национально-демографические, природно-климатические, геополитические, территориальные, ресурсные. В значительной степени их функционирование предопределяется этническими традициями, характером воспитания населения, его миграционной подвижностью и т.д. В этой связи, этнический рынок правомерно определить как систему товарно-денежных отношений, включающую этнические акторы (значимые субъекты, играющие важную роль в функционировании этносистем), а также продвигаемые на рынок товары и услуги, имеющие этнические особенности, соответствующую данному рынку инфраструктуру, визуальные презентации, и, при этом,- информацию, отражающую и характеризующую присущие им особенности.

В теории и практике современной региональной экономики локальный этнорынок трактуется как определенная этнически идентифицируемая подсистема хозяйствования, имеющая «сквозное» строение, которое в своих границах интегрирует макро,- мета-, мезо- и микроэкономические уровни производства и потребления [3, с. 57-82.].

Основными критериями выделения категории этнорынка, согласно принятой авторами трактовке, являются территория, этнокультурная среда и специализация. Они, во многом, предопределяют специфику этнорынков [4, с. 1105-1109].

- Так, территория предопределяет физический формат и границы рынка, его географиче- ское положение. Ее оценка позволяет с большей или меньшей точностью выявить количество проживающего населения, особенности природно-климатических факторов, экологическую обстановку, позиции пограничного (или внутреннего) положения по отношению к другим странам и регионам, имеющуюся транспортную инфраструктуру и проч.

- Этнокультурная среда отражает культурные, религиозные, национальные и иные особенности, в т.ч. традиции, обычаи, подходы к воспитанию молодого поколения, учитывающие этнические принципы, распространяющиеся на народонаселение локальной территории. Они, несомненно, влияют на производство товаров и услуг, обусловливают поведение потребителей данного этнорынка, выступают в качестве важнейшего аспекта целесообразности входа и присутствия на нем производителей товаров и услуг этнической оринетации, розничных торговых посредников, продавцов, организаторов перевозок товаров и др. участников рынка.

- Специализация определяет разновидность товаров (товарной группы) или услуг, которые предлагаются на данном рынке. Она диктуется как территориальными критериями, так и историческими предпосылками размещения этнопоселенческих пунктов, определенных производств и рыночной инфраструктуры. Сформировавшаяся специализация в настоящее время поддерживается странами и регионами как своего рода «торговая марка». Такими примерами на Северном Кавказе могут быть кубачинские изделия из серебра, кавказские минеральные воды, адыгейский сыр и др.

Выявление тенденций развития этнорынков свидетельствует о том, что их расширение, или, наоборот, «сжатие» зависит от некоторых факторов, в числе которых следующие:

- общая социально-экономическая ситуация, развитость рыночных отношений в стране и регионах, в целом;

- геополитическое положение и позиции конкретной территории;

- концентрация на определенной территории населения, имеющего в своих потребительских предпочтениях этноориентированные установки, запросы, потребности;

- наличие производителей товаров и услуг, способных удовлетворять такие потребности и поддерживающих сооветствующую рыночную среду; 
- насыщенность территории (в т.ч. при компактном проживании на ней населения, имеющего этноориентированное поведение) рынками (как местами торговли), а также магазинами с филиально-сетевыми структурами, составляющими конкуренцию местным продавцам, в значительной мере, «нивелирующими» местное товарное предложение, и способствующими, при этом, сужению пространства этнорынков потребления [5, с. 70-73].

В реальной экономике местные компании зачастую используют выбранный локальный рынок как стартовый, и если их продукция пользуется спросом и объемы продаж растут, быстро расширяют сферу продаж на рынки других регионов, а в дальнейшем и стран. Тем не менее, часть из них в силу различных обстоятельств не продвигается дальше локального уровня. Но это не будет означать, что такие производства убыточны или не имеют перспектив на рынке - присутствие и четкая ориентация на данный рынок является стратегической целью таких производителей. Это свидетельствует о том, что помимо крупных транснациональных и российских производственных компаний и поставщиков, действующих на потребительском рынке, существуют локальные компании, конкурентные стратегии которых в перспективе нацелены на сохранение рынка или, при возможности, расширение своего присутствия.

Субъектная определенность: участники этнических рынков. Участниками этнического рынка выступают, с одной стороны, потребители товаров, предъявляющие спрос на продукцию, реализуемую на такого рода рынках, а с другой ее производители и продавцы, заинтересованные в продаже товаров, продвигаемых на целевые сегменты рынка.

Для понимания особенностей этнорынков и поведения на них всех участников, целесообразно последовательно проанализировать потребителей и производителей, поставляющих на рынки этноориентированные товары, а также их конкурентов, партнеров и т.д. С этой целью возможно использование мезоэкономического анализа. Он предполагает составление представления о регионе, в границах которого развивается конкретный этнорынок, а также об отраслях и компаниях, малых предприятиях и индивидуальных хозяйствах, участвующих в его формировании, об инфраструктуре, логистике и др.

Потребители, ориентированные на тради- цционные продовольственные товары. В рамках выполнения Гранта «Хозяйственные практики народов Северного Кавказа: этноэкономика век XX1» авторами был проведен анализ потребителей данного макрорегиона, выступающих одной из сторон этнорынков, локализующихся на его территории. При этом выявлены особенности потребительского поведения, возможности и факторы развития такого рода рынков, на которых продаются товары, востребованные покупателями, имеющими специфические вкусы, запросы, пристрастия [6, с.116-121].

Для дополнения проведенного таким образом маркетингового анализа необходимым представляется, как подчеркивает Березин И.С., изучение потребителей, как носителей общих социальных признаков, образующих определенный сегмент рынка [7, с.19].

\section{2. Ориентация этнорынков регионов} Юга России на удовлетворение спроса целевых аудиторий потребителей

В формате изучения влияния этнорынков на удовлетворение потребностей населения конкретных регионов, в частности, в связи с компактным проживанием в них коренных народностей и этнических групп, продолжается дискуссия о природе этноса (от греч. ethnos народ, племя). Его, как правило, характеризуют как устойчивую совокупность людей, объединенных общими объективными или субъективными признаками [8]. Одним из обсуждаемых в этой дискуссии вопросов является такой, как: существует ли этническая группа объективно или является субъективно сформированным образованием, выступая в качестве определенного образа самоидентификации.

В значительной части монографий и статей высказывается утверждение о том, что этногруппа рассматривается как часть сообщества, способная к самоорганизации для взаимодействия с обществом и государством на альтернативной или дополняющей основе. Ее члены воспринимают отличительные признаки в качестве объединяющей платформы и утверждают тезис относительно общего происхождения или общей истории. Этногруппа отличается аскриптивными признаками - общим языком, культурой (письменность, праздники, обычаи, религия и др.), цветом кожи людей, их географическим местом рождения и, как правило, проживания. Эти признаки выступают в качестве 
этнокорпоративных стереотипов и находятся вне индивидуального контроля. В авторском понимании этнические группы существуют объективно, отражая разнообразие проживающего в современных условиях населения.

Потребительское поведение этногрупп включает в себя осознание присущих им потребностей, интересов, финансовых возможностей осуществления покупок, способы их выбора, а также торг, обслуживание потребителей, использование купленных товаров. Оно предполагает многократное повторение данного цикла применительно к разным товарам и в различное время. Анализ потребительского поведения предполагает обозначение конкретного рынка товаров и услуг. С учетом этого, этнорынок представляет собой форму социального взаимодействия между продавцом и покупателем, «окрашенную» особенностями потребительских предпочтений. Одной из структурных площадок, на которых это происходит, является рынок потребительских товаров и услуг, который и является сферой изучения специфики потребительского поведения.

Первоначально для исследования потребительского поведения с позиций маркетинга было характерно фокусирование внимания на отдельном индивиде-потребителе. Потребности клиента рассматривались как врожденные, а не сформированные обществом или рынком, поэтому перед фирмами ставилась задача «поймать потребителя на крючок», предлагая товары или услуги, удовлетворяющие его потребности лучше, чем то, что предложено конкурентами [9, с. 84]. Позже понимание групп потребителей значительно расширилось, в т.ч. за счет введения понятия «целевые аудитории» [10, с.292].

В последние годы признание тенденции к сохранению и развитию этнической самоидентичности населения нашло отражение и в потреблении. Это проявляется в том, что все более заметно стремление части населения демонстрировать в потреблении свою этническую принадлежность. При этом. возрождаются забытые атрибуты традиционной культуры, а также появляются новые, вводимые в современную моду.

Наступление эпохи постфордизма, характеризующегося господством гибких технологий, позволяющих выпускать продукцию мелкими партиями без ущерба для цены, материально подкрепило тенденцию ухода от стирающего этнически-обусловленные границы массового потребления. Во многих странах стал развиваться бизнес, связанный с культивированием у потребителей тяги к символам этнической принадлежности (национальные блюда, элементы традиционной одежды, ковры, ремесленные сувенирные изделия и т.п.). Если эта тенденция будет усиливаться, то роль этнического фактора в потреблении также будет возрастать [11, p.21-40]. Для маркетологов этническая пестрота потребителей означает изменение сегментации рынка, выделение новых целевых аудиторий. Каждая этническая группа выступает как особый сегмент, предъявляющий специфический спрос, удовлетворение которого может приносить немалую прибыль[12, р.204-205].

В целом, правомерно заключить: наличие этнокультурной мотивации поведения потребителей из числа четко выделяющихся этногрупп, очевидно. При доминировании массовой (не акцентированной) культуры потребления у значительной части населения мира, в целом, и России, в частности, именно ориентированность на этническую самоидентичность имеет тенденцию к усилению в многонациональных регионах. Одной из таких территорий являются регионы Юга России, в частности, Северного Кавказа.

В современном административно-территориальном состоянии республики, в которых проведено исследование, представляют собой регионы, входящие в состав Северо-Кавказского федерального округа (кроме них, в округ входит также Ставропольский край). Эти республики следующие: Республика Дагестан, Республика Ингушетия, Кабардино-Балкарская Республика, Карачаево-Черкесская Республика, Республика Северная Осетия-Алания, Чеченская Республика. Кроме того, в число кавказских республик нередко включают Республику Адыгею, входящую в Южный федеральный округ [13, с. 18-238].

Общие тенденции развития демографического потенциала республик Северного Кавказа, которые. во многом, отражают специфику целевых аудиторий потребителей, можно сформулировать следующим образом:

1. Высока доля населения, имеющего высшее образование $-31,5 \%$, при том, что среднее профессиональное образование имеют 28,7\%, среднее общее -20,8\% [13, с.155-192]. Это подтверждает стремление населения республик Северного Кавказа иметь достаточно высокий уровень образования, которое здесь весьма ценится. 
2. Велика доля населения молодых возрастов - удельный вес населения моложе трудоспособного возраста - 26, 2\%, что существенно выше, чем по России, в целом. (Для сравнения, в регионах соседнего Южного федерального округа доля детей и подростков составляет только 17,1\%). Удельный вес населения в трудоспособном возрасте значителен - 58,7\%, а старше трудоспособного, наоборот, относительно мал 15,8\%. В Южном же федеральном округе, в целом, доля пенсионеров, например, превышает 26,7\% [13, с.45-52].

3. Среднедушевые денежные доходы населения республик существенно ниже, чем по Российской Федерации, в целом (по РФ они составляют более 34,0 тыс. руб. в месяц) [13, с. 228-276]. Так, в Республике Ингушетии расходы на душу населения составляют 15,6 тыс.руб. в месяц, в Карачаево-Черкесской Республике - около19тыс.руб., что является одними из самых низких показателей в России. (При этом, речь идет только об учтенных доходах).

4. Сформулированные выше две позитивные тенденции относительно образовательного и возрастного состава населения республик Северного Кавказа (относительно высокая доля населения, имеющего высшее и среднее образование и более молодое по возрасту население), к сожалению, сопровождается высоким уровнем безработицы на Северном Кавказе - до 5-8\%, особенно, в Республике Ингушетия (до 15,7\%), и Чеченской Республике. Это одни из самых высоких показателей в стране. Однако, следует отметить изменение положение к лучшему. Например, в начале двухтысячных годов безработица в этих регионах достигала $30 \%$ и более. В последние же годы в регионе, в частности, в Чеченской Республике, введено в строй большое число предприятий в сфере перерабатывающей, домостроительной и др. отраслей промышленности, а также сельского хозяйства и строительства. Это обеспечило реальный рост числа рабочих мест, снижение безработицы, рост доходов.

При этом, высока доля занятого населения, работающего в секторе полунатурально-домохозяйственного уклада.

Такой уклад относится к традиционному архаичному типу хозяйствования, преобладающему в этноэкономическом сегменте хозяйственных комплексов ряда национальных республик Северного Кавказа и Нижнего Поволжья. Субъектами этого уклада являются домохозяйства автохтонных этносов, проживающих в горных и предгорных местностях, с низким экономическим потенциалом и невысоким уровнем рыночной освоенности [5, с.74-75]. Эта особенность организации производства, в частности, продуктов питания, предопределяет наличие большого числа локальных продовольственных рынков.

В такой ситуации превалирует тенденция продажи значительных объемов продовольствия в небольших магазинах, лавках и в рыночных павильонах, особенно, в сельской местности. Сетевые торговые структуры не получили здесь значительного распространения, вследствие чего. сохраняется локальная продажа мясных и молочных продуктов, овощей, фруктов, выпечки. Так, объем продажи товаров на розничных рынках и ярмарках в регионах Северного Кавказа в 2016 г. составлял свыше 425 млрд. руб., [13, с. 904-1034], и размеры таких продаж растут.

Вышеперечисленные тенденции, сложившиеся в экономической деятельности анализируемых республик, в немалой степени, предопределяющие специфику хозяйственно-бытового уклада проживающего здесь населения и его потребительского поведения, дают основания для ряда выводов и обобщений.

Они изложены с учетом результатов опросов населения относительно потребления мясной и молочной продукции в двух республиках - Карачаево-Черкесии и Адыгее, осуществленных в апреле - июне 2017 г. Данные исследования были проведены, по существу, повторно. Результаты подобного же исследования были опубликованы в 2011 году [14, с.42-108]. Их анализ показал высокую схожесть в характере ответов.

Выявление особенностей спроса местного населения на мясо, молоко и продукты из них проводилось путем интервьюирования как покупателей (196 респондентов), так и 12 продавцов мясной и молочной продукции. Обобщение результатов опроса позволило сформулировать следующие особенности покупательского поведения, выявить роль этнорынков регионов Юга России в удовлетворении спроса целевых аудиторий потребителей.

1. Имеет место устойчивая ориентация на конкретные продукты. Так, потребители Карачаево-Черкесской Республики покупают мясные и молочные продукты практически ежедневно (61\% опрошенных). При этом, как выяснилось, покупатели приобретают, в основном, сырое охлажденное мясо у проверенных продавцов, что- 
бы быть уверенным в его качестве и свежести. При этом, некоторые потребители содержат мясной и молочный скот в собственном хозяйстве, что обеспечивает натуральное потребление их семьёй качественных домашних продуктов (более $20 \%$ опрошенных). Обобщение результатов опроса показало, что спрос на мясомолочную продукцию в торговой сети, например, Карачаево-Черкесии является стабильно высоким. В ассортименте анализируемых небольших торговых точек (магазины у дома, мясные лавки) присутствует сырое мясо халяль (говядина, баранина, конина), сырое молоко, полуфабрикаты (переработанные субпродукты, копченое и сушено-вяленное мясо). Предпочтения потребителей относительно мясной продукции одного из сел этой республики представлены в таблице.

В некоторых торговых точках республик Северного Кавказа продают готовые к употреблению продукты (домашняя колбаса из конины, хычины, манты и др.). Они также пользуются спросом как у местного населения, так и у туристов. Как показал анализ, ассортимент специфических молочных продуктов также достаточно большой: айран, каймак, домашняя сметана, рассольный сыр и др. По свидетельству продавцов, такая продукция пользуется неизменным спросом.

Удельный вес специфических национальных мясных и молочных продуктов в ассортименте всей продукции составляет, по словам опрошенных, от 40 до 65\%, что косвенно подтверждает стабильный спрос на данные продукты.

В Адыгее, например, высоковостребован- ными являются такие молочные продукты, как адыгейский сыр (куае), айран, копченый сыр, сливки, сметана.

2. Изучение ориентации потребителей на цену мясомолочной продукции показало, что в Карачаево-Черкесской Республике цена не является основным фактором при покупке. Правомерно сделать вывод о том, что производители данного локального рынка удерживают довольно низкие наценки на мясную и молочную продукцию. Многие из них ориентируются на конкретных, вплоть до лично знакомых, потребителей. Инфляционные процессы последних лет в экономике страны, конечно, привели к удорожанию продуктов питания. Вследствие этого реальный спрос на них снизился. Однако, в целом, ориентация на регулярное употребление мяса в рационе жителей республики осталась. В то же время, в Республике Адыгея приобретение мясных и молочных продуктов в последние 4 года сократилось более, чем на $20 \%$.

3. Культурно-нравственная составляющая образа жизни потребителей является очень важным фактором в потребительском поведении, в частности, сельских жителей Карачаево-Черкесской Республики. Приготовление и потребление пищи тесно связано с религиозными обычаями и традициями, и это обстоятельство строго учитывается производителями и продавцами реализуемых продуктов. Например, в мясных павильонах и магазинах сел республики практически невозможно увидеть в продаже свинину, так как по обычаям ислама это мясо запрещено употреблять мусульманам в любом виде [15]. При

Таблица. Распределение ответов на вопрос «Какую специфическую национальную мясную продукцию Вы потребляете?» респондентов, проживающих в с. Учкекен (Карачаево-Черкесская Республика),\%

\begin{tabular}{|c|c|c|c|c|}
\hline \multirow{2}{*}{$\begin{array}{c}\text { Распределение ответов } \\
\text { респондентов }\end{array}$} & \multicolumn{4}{|c|}{ Виды национальной мясной продукции } \\
\hline & Вяленое мясо & Сохта & Джерме & Къыймала \\
\hline \multicolumn{5}{|l|}{ По возрасту } \\
\hline - до 30 лет & 11 & 32 & 33 & 13 \\
\hline - от 30 до 45 лет & 30 & 29 & 22 & 26 \\
\hline - старше 45 лет & 59 & 39 & 40 & 61 \\
\hline \multicolumn{5}{|l|}{ По полу } \\
\hline - женщины & 41 & 45 & 42 & 38 \\
\hline - мужчины & 59 & 55 & 58 & 62 \\
\hline \multicolumn{5}{|l|}{ По доходу на семью } \\
\hline - менее 15000 руб. в мес. & 21 & 31 & 12 & 18 \\
\hline - от 15001 до 40000 руб. в мес. & 33 & 33 & 10 & 15 \\
\hline - более 40001 руб. в мес. & 15 & 18 & 14 & 11 \\
\hline
\end{tabular}

По данным анкетного опроса 164 потребителей мясомолочной продукции, проведенного авторами в с. Учкекен, Карачаево-Черкесская Республика (апрель-май 2017 г.) 
этом, большой популярностью пользуется говядина и баранина, обычно с пометкой «халяль», т.е. дозволенное шариатом (в данном контексте обозначает особый процесс убоя скота и не запрещенные мясные продукты). Слово «халяль» может являться даже составной частью названия магазина или торгового павильона на рынке или ярмарке.

4. Экологическая чистота продуктов питания является важным обстоятельством при покупке для большинства опрошенных потребителей. Именно этот фактор назвали в качестве важнейшего 59\% опрошенных. Информация, имеющаяся у покупателя по поводу места происхождения приобретаемой мясомолочной продукции, либо выращивание скота в личном подсобном хозяйстве, значительно повышает для него экологическую «привлекательность» и полезность мяса и молочных продуктов. Весьма важны также: санитарно-гигиеническая безопасность (42\% ответов), свежесть (38\%), отсутствие генетически-модифицированных добавок - например, в полуфабрикатах (14\%). Озабоченность части опрашиваемых потребителей Адыгеи проблемой ГМО, относительно которых действуют стандарты в каждой стране [16, с.127], подтверждает понимание населением Северного Кавказа значимости здорового образа жизни. Это актуализирует учет природохозяйственных факторов при организации производств на Юге России, внедрения природоохранных технологий в растениеводстве и животноводстве [17, c.359].

5. Потребительское поведение сельских жителей Карачаево-Черкесской республики отличается высокой степенью традиционности и незначительной готовностью к изменениям. Большинство покупателей постоянно ходят в один-два магазина или к ранее знакомым продавцам на рынке (82\% опрошенных). Вследствие этого, производителям и продавцам заранее известно, кто будет их покупателями. Большую долю в повседневном рационе населения занимают национальные мясные блюда (более 40\% опрошенных). Население Карачаево-Черкесии в возрасте старше 50 лет (особенно мужчины) охотно покупает специфические мясные продукты, в то время как молодые покупатели (возраст до 25 лет) к таким продуктам проявляют существенно меньше внимания.

Сформулированные особенности показывают, что почти все местные жители республик
Северного Кавказа придерживаются национальных традиций в питании. В связи с этим деятельность участников исследуемых локальных рынков характеризуется высокой степенью этноориентированности и замкнутости на внутренних поставщиков. Это является отчасти положительным фактором, но такая замкнутость дает слабый импульс для развития, к примеру, мясомолочного производства республик в существенно больших размерах, при имеющемся колоссальном ресурсном потенциале данных территорий.

Таким образом, исследование проблемы развития этнорынков в структуре экономического пространства регионов Юга России позволяет резюмировать его следующим образом.

1. Локальные этнорынки представляют собой рыночные сегменты национальной экономики, выделяемые по географическому, национально-этническому, товарному, функциональному и другим признакам, функционирование которых предполагает территориальную ограниченность, концентрацию на одном или нескольких сегментах, отличающихся этноэкономической спецификой. На локальных этнорынках действуют рыночные субъекты в рамках соответствующих сегментов, т.е. в отношении групп потребителей, одинаково реагирующих на один и тот же предлагаемый продукт и комплекс маркетинга. Оценивая имеющиеся в данной плоскости исследования, можно сделать заключение о том, что это - относительно новая, претендующая на самостоятельную область знаний, важнейшая сфера этноэкономических исследований, маркетинговых разработок, регионалистики, экономгеографии.

2. Изучение вопросов устойчивости наличия этнокультурной составляющей в потребительском спросе покупателей, проживающих в республиках Северного Кавказа, показало ее значимость. Особенно это присуще территориям, где компактно проживает население, имеющее устойчивую приверженность к определенным продуктам питания, видам и цвету одежды. Данная тенденция отчетливо проявляется, например, при потреблении мясомолочных продуктов, в частности, в регионах проживания населения, исповедующего ислам, иудаизм, буддизм. Это актуализирует вопросы ориентации этнорынков регионов, например, Юга России на удовлетворение спроса целевых аудиторий потребителей. При этом выявлено, что потреби- 
тельское поведение жителей Северного Кавказа неоднородно, оно различается в зависимости от места их проживания, сложившихся традиций, воспитания и т.д.

3. Проведенный анализ показал, что производители и поставщики продуктов питания чаще всего действуют в мультинациональной среде, в которой сильны локальные факторы, при существенном влиянии глобальной интеграции. Ключевым фактором успеха на таких рынках является адаптация производителей к местным условиям, учет вкусов и потребностей покупателей, во многом предопределяемых конкретной этнокультурной составляющей.

4. Оценка позиционирования этнорынков в структуре рыночно-экономического пространства регионов Юга России показала, что такого рода рынки повышают возможности локализации трудовой активности и коммерческой дея- тельности, в т.ч. в этноориентированном малом бизнесе, приближения его к локальным узлам трансакционной активности, стимулируя их ориентацию на удовлетворение спроса целевых аудиторий потребителей в конкретных регионах. Признание их специфики предполагает учет таких особенностей в моделях поведения компаний, ориентированных на максимальное удовлетворение покупательского спроса и повышение, при должном учете данного фактора, своей конкурентоспособности. Особенно значимо понимание значимости потребления населением специфических продуктов питания и готовых блюд кавказской кухни.

Статья подготовлена при поддержке гранта РФФИ (проект 18-010-00283 «Морфология экономического пространства региона: междисциплинарный подход»).

\section{Библиографический список}

1. Словарь терминов [Электронный ресурс]. Режим доступа: www.glossary.ru, свободный

2. Этнические рынки в России: пространство торга и место встречи: Монография / Науч.ред. Дятлов В.И., Григоричев К.В.- Иркутск: Изд-во ИГУ, 2015. 342с.

3. Гранберг А.Г. Региональная экономика и региональная наука в России: десять лет спустя// Регион: экономика и социология. 2004. № 1. С. 57-82.

4. Кетова Н.П., Овчинников В.Н. Этническая мотивация потребительского поведения покупателей на продовольственных рынках Северного Кавказа // Экономика и предпринимательство. 2016. № 8 (73). С. 11051112

5. етова Н.П., Овчинников В.Н. Институты развития в многоукладных экономиках периферийных регионов //Проблемы прогнозирования. 2014. № 2. С. 68-76.

6. Традиционные хозяйственные практики народов Северного Кавказа: этноэкономика - век XX1: Монография / Под ред. Колесникова Ю.С., Овчинникова В.Н. Ростов-на-Дону. 2017. 192с.

7. Березин И.С. Маркетинговый анализ. Рынок. Фирма. Товар. Продвижение. Москва. 2007. 480с.

8. ЭТНОС [Электронный ресурс]. Режим доступа: https://yandex.ru/search/?1r=39\&clid=2242347 \&text=\%D0\%AD \%D0\%A2\%D0\%9D\%D0\%9E\%D0\%A1, свободный

9. Ольсевич Ю. Хозяйственная система и этнос // Вопросы экономики. 1993. № 8. С.12-16.

10. Багиев Г.Л., Кетова Н.П. Маркетинг в отраслях и сферах деятельности. Санкт-Петербург.2016. 339с.

11. Glazer N., Moynihan D.P. (Eds.) Ethnicity: Theory and Experience. Cambridge, MA: Press \& Harvard University Press. 1975

12. Marketing in a multicultural world: ethnicity, nationalism, and cultural identity / Janeen Arnold Costa, GaryJ. Bamossy, editors. Thousand Oaks, Calif.: SAGE Publications, 1995

13. Регионы России. Социально-экономические показатели. 2017. Стат.сб. Москва. 2017. 1402с.

14. Кетова Н.П., Тимченко Е.Ю. Этномаркетинг как концепция деятельности компаний на локальных продовольственных рынках. Ростов-на Дону. 2011. 132с.

15. Халяль и нехаляль продукты [Электронный ресурс]. Режим доступа: http:/www.umma.ru/questions/halalproducts/, свободный.

16. Айзинова И.М. Проблемы продовольственной безопасности в сфере потребления: региональный аспект// Проблемы прогнозирования.-2015-№ 6. С 125-130.

17. Овчинников В.Н., Кетова Н.П. Природохозяйственные императивы структурной организации экономического пространства региона // Экономика и предпринимательство. 2018. № 9 (98).С.356-361. 